\title{
POLYAMIDE 11 POROUS FILMS BY NIPS: THE INFLUENCE OF MISCIBILITY AND POLYMER CRYSTALLINE FORMATION IN PORES STRUCTURE AND MORPHOLOGY
}

\author{
Rayanne Penha Wandenkolken Lima ${ }^{a, *,(1)}$, Thieres Magaive Costa Pereira ${ }^{a}$ and Eloi Alves da Silva Filho ${ }^{a}$ \\ a'Departamento de Química, Universidade Federal do Espírito Santo, 29075-910 Vitória - ES, Brasil
}

Recebido em 29/07/2020; aceito em 29/01/2021; publicado na web em 24/02/2021

\begin{abstract}
This study described the morphology, crystallinity, thermal and mechanical characterization of Polyamide 11 (PA11) porous film prepared by non-solvent induced phase separation (NIPS) method using formic acid (FA) as solvent. In addition, the miscibility of PA11/FA/ $\mathrm{H}_{2} \mathrm{O}$ system was performed to generate a ternary phase diagram. The porous films morphology was investigated by Scanning Electronic Microscopy (SEM) analysis, the crystallinity by X-Ray Diffractometer (XRD) and thermal study by Differential Scanning Calorimetry (DSC). A cellulosic reinforcement was used in porous films and the stress-strain analysis was performance by Dynamic Mechanical Analysis (DMA). The porous films were prepared with polymer composition of 15, 20 and 25 wt $\%$. The porous films showed different microstructure in function of polymer concentration. The 20 and $25 \mathrm{wt} \%$ porous films showed micropores structures with medium pores diameters between $0-10 \mu \mathrm{m}$ calculated by image analysis. The XRD analysis show predominance of $\alpha$ crystalline form of polymer at 20 and $25 \mathrm{wt} \%$ porous films. The degree of crystallinity increases with polymer concentration increase. The stress-strain analysis of porous films shows a proportional dependence of Young's modulus with the increase of polymer concentration in each film.
\end{abstract}

Keywords: polymer; crystallinity; DSC; DMA; cellulose.

\section{INTRODUCTION}

The membrane separation process (MSP) is an advanced and efficient technique that possesses great demand and industrial implementation at the present day. Currently, membranes are one of the most widely used and researched unitary separation processes within the chemical technologies applied to industry, being implemented in the area of biotechnology, medical treatments, drug purification, milk protein concentration, dye recovery, purification of waters, among others. ${ }^{1-3}$ The MSP is an energetically more favorable operation than the classic process like distillation, evaporation and cryogenics processes. Another advantage is the flexibility of using membranes in industrial plants and ease of logistics in operating systems, which can be implemented at a local or global level. ${ }^{4}$

The environmental concern with the generation of unsustainable waste has been growing in the economic and industrial sectors. The Global Market Study on Membranes Separation reported that membrane market growth between years of 2013 to 2019 and reach an estimated value of US $\$ 39.2$ billion in $2019 .{ }^{5}$ In this context, research that seeks alternative solutions in the development of new materials it is becoming usual.

According to IUPAC's Golden Book, ${ }^{6}$ film is definited as all condensed material that presents itself in one dimension. As the membranes have widths much larger than their thicknesses, they are included in the definition of films. But membranes can also be classified according to their composition, synthetic or biological, such as the cell porous film. The membrane material physical-chemical properties enable the membrane filtering characteristic, and it is dependent of the pore size and its directed to filtration of solid-liquid, liquid-liquid and gas-liquid mixtures. ${ }^{7}$ The flow of material between these phases is known as permeate and the predominant mechanism in transport is diffusion. Membranes may be composed of several types of materials, such as ceramic, metallic, carbonaceous and polymeric. ${ }^{3}$ Among these, polymeric materials are highlighted by

*e-mail: rayannepwlima@outlook.com the diversity of uses, combinations with new matrices and, in some cases, the reduction of the environmental impact using polymeric matrices of vegetable origin. Most of the membranes used in industrial separation processes are composed of glassy polymers due to their high selectivity, low permeability and good mechanical properties. ${ }^{2}$ In addition to these factors, the choice of polymer type is a critical decision and polyamides are a group of semi-crystalline materials with good potential membrane composition. ${ }^{3}$ The main advantage of polyamides is that their provides excellent proprieties such as high mechanical strength, chemicals resistances; good flow ability, high water absorption, thermal stability and excellent cost/performance balance. $^{4}$

Several studies ${ }^{8-11}$ address the use of polyamides as material for preparing polymeric membrane using the phase inversion (PI) method. Synthetic membranes may be accomplished by several techniques as stretching, sintering, solution coatings, phase inversion and electrospinning. The non-solvent induced phase separation (NIPS) is the most versatile technology that allows the preparation of asymmetric membranes. The NIPS use a homogeneous polymer solution that is immersed in a coagulation bath composed by a nonsolvent. The coagulation bath allow that the polymer dissolved in solvent passes from the fluid states to the solid state to give ride to the formation membranes. The membranes structure and morphology are controlled by the thermodynamic and kinect parameters of phase separation of membrane forming.

Aulova et al. ${ }^{12}$ investigated the permeability of drugs in polyamide 6,6 (PA 6,6 or nylon 6,6 ) membranes prepared by NIPS. The authors explain that membrane porosity is associated with a high affinity between solvent and non-solvent where different precipitation kinetics result in changes of membrane morphology. The study carried out by Bugatti et al. ${ }^{13}$ developed the use of polyamide 11 (PA11) as a polymeric matrix in capillary membranes. The authors used bio-based PA11 and a hybrid compound of hallo site nanotubes (HNTs aluminium-silicate compound) with lysozyme filling (antimicrobial molecule). The membrane morphology showed fibers with an average diameter between 0.3 to $0.5 \mu \mathrm{m}$, there was a good interaction 
between PA11 and HNT particles, generating an improvement in the mechanical properties of the fibers. The PA11 is a bio-based polymer, also known as bioplastic, $100 \%$ renewable that has low net $\mathrm{CO}_{2}$ emissions and low global warming potential. ${ }^{13,14}$ Although, the use of PA11 there are few studies available in the databases on membranes of porous film structure. The development of green chemistry in the industrial sector, it favors the use of membranes, and within the concepts of green chemistry, polymers are also an important component in meeting the goal of producing a more environmentally sustainable membrane.

The selection of solvent is another important factor that influence in membrane morphology prepared by NIPS. Several authors in the literature ${ }^{3,15-17}$ have investigated different solvents for polyamide solubilization such as formic acid, hydrochloric acid, methanol and calcium chloride solutions, m-cresol or N-methyl-2-pyrrolidone. Among these, formic acid (FA) is commonly used for solubilization of aromatic and aliphatic polyamides and is also used as a solvent for polyamide 11 and polyamide $12 .{ }^{18}$ The study of the ternary diagram allows a good approximation of the real behavior of the system under study, being able to predict whether the combination of the three components is ideal for the formation of the membrane. ${ }^{19}$ Mazinani et al..$^{20}$ approach the study of the ternary diagram as a qualitative description of the membrane formation process. The authors highlight the analysis of the cloud point curve as an important aspect in the study of membrane formation.

Finally, the membrane materials are an important influence factor of membrane structure and morphology. The specificity of the use of each material is directly associated with its physical and chemistry proprieties. In case of polymers, the most important is the mechanical property and the development of news materials or reinforcement became usual. Cellulose and lignocellulose fibers are cited as an alternative to traditional reinforcement materials, such as fiberglass, as they have good intrinsic properties, high tensile strength, are sustainable and biodegradable. ${ }^{21}$

In order to evaluate all these conditions already cited this study aims to investigate the miscibility of the polyamide 11 , formic acid and water using the ternary diagram to preparation of polyamide 11 porous films by NIPS. After wards intends to analyses the morphology, thermal characters, structural and the mechanical proprieties of porous films. In addition, in case of mechanical the porous film reinforcement with cellulose fibers will be analyses and compare the effect of each concentration on the porous films. All these studies have been carried out to analyze the potential use of these porous films in permeation processes that will be carried out in the future.

\section{EXPERIMENTAL}

\section{Materials}

Polyamide 11 (PA11) granules were provided by Sigma-Aldrich (CAS 25035-04-5) with melt temperature (Tm) of $198{ }^{\circ} \mathrm{C}$, glass transition temperature $(\mathrm{Tg})$ of $46^{\circ} \mathrm{C}$ and density of $1.026 \mathrm{~g} . \mathrm{mL}^{-1}$ at $25.0^{\circ} \mathrm{C}$. As solvent formic acid (FA) $98 \%$ (CAS 64-18-6) from Neon was selected with density of $1.240 \mathrm{~g} \cdot \mathrm{mL}^{-1}$ and boiling temperature of $101{ }^{\circ} \mathrm{C}$. Deionized water was chosen as non-solvent for the ternary system. The cellulose fiber was provided by the company SUZANO (Aracruz, ES - Brazil) in the form of sheets composed of $90 \%$ of cellulose bleached by the Kraft method.

\section{Miscibility gap analysis}

The interaction between the components of the PA11/FA/ $\mathrm{H}_{2} \mathrm{O}$ system was studied to determine the miscibility interval of the ternary diagram and thus evaluate the porous film formation system. The diagram was constructed by determining the cloudpoint curve of different polymer concentration by titration of water. In the literature for analysis of the cloud point, the concentration range of polyamide 6 (PA6) normally used in the preparation of membranes is 15 to $20 \mathrm{wt} \%{ }^{12}$ As polyamide 11 (PA11) has characteristics similar to polyamide 6 , a similar concentration range was adopted for the preparation of solutions. The compositions solutions of 2.5, 5.0, 10 and $15 \mathrm{wt} \%$ of PA11 and formic acid was formulated. These solutions were stirred for 30 minutes at $120^{\circ} \mathrm{C}$. After cooling at room temperature, water was added to the solutions by titration until permanently turbid. Following, the systems were kept at rest for 24 hours and continued turbidity was ensured. The ternary diagram composition was then calculated from the amount of non-solvent, solvent and polymer present in each system at room temperature.

\section{Porous film preparation}

The PA11 granules was dried in vacuum drying chamber at $80{ }^{\circ} \mathrm{C}$ for $24 \mathrm{~h}$. This step was essential for remove water adsorbed on the surface of the polyamide granule during its storage. Formic acid and PA11 were mixed and kept closed in Pyrex@) glass containers $(25 \mathrm{~mL}$ capacity) for 24 hours. This step allows the polymer to swell by the solvent. After that, the system was mixed using a magnetic stirrer at $120^{\circ} \mathrm{C}$ for $30 \mathrm{~min}$. The closed glass containers avoid formic acid loss by evaporation process.

Each system was formulated to have concentrations of 15, 20 and $25 \mathrm{wt} \%$ of PA11/formic acid and were respectively named by $\mathrm{MPA}_{15}, \mathrm{MPA}_{20}$ and $\mathrm{MPA}_{25}$.

The porous films were prepared by the non-induced phase separation (NIPS) method. Each polymer solution was cooled to reach room temperature for 10 minutes. In sequence, the solution was spread on a glass surface by a stick and the pre-evaporation of the polymer-solvent film was carried out for 2 minutes. The glass plate was immersed in a coagulation bath using deionized water as a non-solvent. After polymer precipitation and total film detachment of the glass plate, they were washed with deionized water and left in the water bath for 24 hours to remove solvent excess.

For characterization, the porous films samples were dried in vacuum oven for 24 hours at $80{ }^{\circ} \mathrm{C}$. In order to compare the porous film morphology, a polyamide 11 dense film (named by PA $11_{\text {film }}$ ) was prepared by pressing polyamide 11 granules on a hydraulic press (Caver) at 5,000 $\mathrm{Pa}$ and $245^{\circ} \mathrm{C}$ for 5 minutes.

\section{Cellulosic reinforcement of polyamide porous film}

The cellulose sheets were previously ground with a 35 mesh screen. Then cellulose was treated with $5 \% \mathrm{NaOH}$ solution at room temperature under homogeneous stirring for 4 hours. The obtained pulp was washed for $\mathrm{pH}$ neutralization and dried at 80 ${ }^{\circ} \mathrm{C}$ for 24 hours. Acid hydrolysis was carried out with sulphuric acid $(10 \mathrm{~mL}$ of concentrated acid to $20 \mathrm{~mL}$ of deionized water) with stirring and heating at $40{ }^{\circ} \mathrm{C}$ for 1 hour. The pulp was washed for $\mathrm{pH}$ neutralization, dried at $80{ }^{\circ} \mathrm{C}$ for 24 hours and sieved again with a 35 mesh sieve. ${ }^{22}$ The fresh cellulose fibers obtained were characterized in a previous work carried out by Farias $^{23}$ as microcrystalline structure.

The aggregation of the cellulose fibers was performed using a modification of Qua and Hornsby, ${ }^{24}$ in their methodology cellulose was dispersed in formic acid under stirring and heating at $40{ }^{\circ} \mathrm{C}$ for 1 hour. Then the polyamide 11 granules were added, left to stand for 24 hours (swelling step), heated to $120^{\circ} \mathrm{C}$ with stirring for $30 \mathrm{~min}$. 
The phase inversion methodology was used to prepare the porous film. As in the literature there are few researches ${ }^{25}$ on films made of polyamide 11/cellulose, the proportions described in Table 1 were analyzed in this study.

Table 1. Polyamide/cellulose solutions compositions

\begin{tabular}{ccc}
\hline Porous film & Cellulose (wt\%) & Polyamide (wt $\%)$ \\
\hline $\mathrm{C}_{1} \mathrm{PA}_{15}$ & 1.0 & 15 \\
$\mathrm{C}_{1} \mathrm{PA}_{20}$ & 1.0 & 20 \\
$\mathrm{C}_{1} \mathrm{PA}_{25}$ & 1.0 & 25 \\
$\mathrm{C}_{2} \mathrm{PA}_{15}$ & 2.0 & 15 \\
$\mathrm{C}_{2} \mathrm{PA}_{20}$ & 2.0 & 20 \\
$\mathrm{C}_{2} \mathrm{PA}_{25}$ & 2.0 & 25 \\
$\mathrm{C}_{4} \mathrm{PA}_{15}$ & 4.0 & 15 \\
$\mathrm{C}_{4} \mathrm{PA}_{20}$ & 4.0 & 20 \\
$\mathrm{C}_{4} \mathrm{PA}_{25}$ & 4.0 & 25 \\
\hline
\end{tabular}

\section{Porous film characterization}

In short, the main techniques employed involve morphology analysis (Scanning Electron Microscopy - SEM), thermal analysis of the compound (Differential Scanning Calorimetry - DSC), structural analysis (X-Ray Diffraction - XRD) and mechanical analysis (Dynamic Mechanical Analysis - DMA). ${ }^{26}$

\section{Scanning Electron Microscopy (SEM)}

The characterization of film morphology was investigation by a Scanning Electron Microscopy (SEM) JSM-6610LV equipment by a beam with acceleration equal to $30 \mathrm{KV}$, whose value is the energy required for ensure that all elements properly generate their characteristic rays. The upper region and cross section of each porous film were studied. The samples were cooled and cryofracture with liquid nitrogen. Before SEM analysis, the samples were metallized with gold film by the Denton's Desk V equipment.

\section{$X$-ray diffraction $(X R D)$}

The crystallinity and structure of porous films was performed by X-ray diffraction analysis (XRD). The equipment was the D8 - Advance Bruker using $\mathrm{Cu}-\mathrm{K} \alpha$ radiation $(\lambda=1.541 \AA)$ monochromatized by graphite crystal, configured with $40 \mathrm{KV}$ and $30 \mathrm{~mA}$ in a 10 a scan $50^{\circ}(2 \theta)$.

\section{Differential scanning calorimetry (DSC)}

The porous film thermal analysis was performed using DSC Q200 TA Instruments under an inert atmosphere of nitrogen gas $\left(\mathrm{N}_{2}\right)$ at a flow rate of $50 \mathrm{~mL} / \mathrm{min}$ and with a heating rate of $10{ }^{\circ} \mathrm{C} \mathrm{min}{ }^{-1}$ and a ramp from 0 to $250{ }^{\circ} \mathrm{C}$. The data analysis was performed by software TA Instruments Universal Analysis. All measurements and data analysis were in according to ASTM D3418. DSC analysis was used to identify the melting temperature (Tm) and the degree of crystallinity (Xcr) of the porous film samples and the polyamide 11 dense film. In addition, the Xcr of the porous film was calculated by equation 1 , using the enthalpy variation obtained by the area under of the main peak of the DSC curves. ${ }^{12}$

$$
\mathrm{X}_{\mathrm{cr}}=\frac{\Delta \mathrm{H}_{\mathrm{fA}}}{\Delta \mathrm{H}_{100 \%}} \times 100
$$

where $\Delta \mathrm{H}_{\mathrm{fA}}$ is the melting enthalpy variation of the sample and $\Delta \mathrm{H}_{100 \%}$ is the melting enthalpy variation for the $100 \%$ crystalline sample.
For polyamide $11 \Delta \mathrm{H}_{100 \%}=226.4 \mathrm{~J} / \mathrm{g}$ was used. ${ }^{25}$ The enthalpy and degree of crystallinity was mensured in triplicate samples and the statistic analisys was made.

\section{Dynamic Mechanical Analysis (DMA)}

Mechanical analysis was performed on a Perkin Elmer model 8000 dynamic mechanical analyses (DMA), using the stress-strain mode with the tension film clamp for rectangular sample. The parameters of the experiment used were a frequency of $1.0 \mathrm{~Hz}$, a force limit of $10 \mathrm{~N}$ with a load of $0.50 \mathrm{~N} / \mathrm{min}$ and a temperature of 30 and $60{ }^{\circ} \mathrm{C} .{ }^{27}$ The mechanical analysis was performed by the Young's modulus ( $\left.\mathrm{E}^{*}\right)$ which is calculated from the initial slope of the stress-strain curve. ${ }^{28}$ The statistical analysis was carry out by linear fitting using Origin software with ANOVA analysis and confidence level of parameters of $95 \%$.

The Young's modulus measures the stiffness of solid materials using the basic principle of Hooke's Law. The value of this module can be calculated for materials whose length is much greater than its lateral dimensions. ${ }^{29}$ Thus the following equation 2 may be used in the stress-strain tests of materials:

$$
E^{*}(P a)=\frac{\operatorname{stress}(P a)}{\text { strain }}
$$

In polymeric materials, Young's module provides an understanding of the types of behaviours existing in that material, which may present an elastic and an inelastic regime. From a chemical perspective, Young's Module originates from the character of intermolecular forces present in the polymer chain. Kawano et al ${ }^{27}$ claim that the stress-strain curve is sensitive to changes in polymer structure, chain orientation, length and crystalline structure.

\section{RESULTS AND DISCUSSION}

\section{The cloud point analyses}

The ternary diagram represented in Figure 1 summarizes the thermodynamic information of the PA $11 / \mathrm{FA} / \mathrm{H}_{2} \mathrm{O}$ system for porous film formation by NIPS. The study of the cloud point allows a qualitative analyze of thermodynamics behavior of the ternary system. The cloud point curve delimits two regions of the diagram: the region where the compositions are completely stable and the region with the metastable and the unstable phase..$^{30}$ Firstly, it is observed that the ternary systems showed points of turbidity in low water concentration, indicating a higher effect of water molecule in the polymer chain structure. This behavior is exemplifying by de data describe in Table 2, the water concentration decreases with the polymer improvement. Secondly, the region between the cloud point curve and the FA- $\mathrm{H}_{2} \mathrm{O}$ axis indicates the thermodynamic stability of the ternary system and, as visible at Figure 1, this region presents a small area. For that reason, water is determined as an unstable factor of ternary system and it is possible to prepare porous film from solutions with a high polyamide 11 concentration. ${ }^{31}$ The type of morphology and microstructure of porous film formed by phase invention is significantly affected by the phase separation behavior of the polymer solution in contact with non-solvent, which in this case is water. During the coagulation bath the polymer solution demixes may undergo into two competitive processes: solid-liquid separation and liquid-liquid separation. ${ }^{32}$ Gregory et al. ${ }^{33}$ discuss that a solid-liquid demixing results in porous films with spherical pore structure and a liquid-liquid demixing results in porous films with cellular pores. The study of this ternary diagram allows a good approximation of the real behavior of the system under study, being able to predict whether 
the combination of the three components is ideal for the formation of the porous film by phase inversion (PI). ${ }^{19}$

Table 2. Relationship of the experimentally masses of PA11, FA and $\mathrm{H}_{2} \mathrm{O}$ for the construction of the ternary diagram

\begin{tabular}{ccc}
\hline PA11 $(\mathrm{g})$ & $\mathrm{FA}(\mathrm{g})$ & $\mathrm{H}_{2} \mathrm{O}(\mathrm{g})$ \\
\hline 2.029 & 11.83 & 0.062 \\
1.421 & 11.83 & 0.166 \\
1.059 & 11.83 & 0.399 \\
0.534 & 11.83 & 0.897 \\
0.254 & 11.83 & 0.997 \\
\hline
\end{tabular}

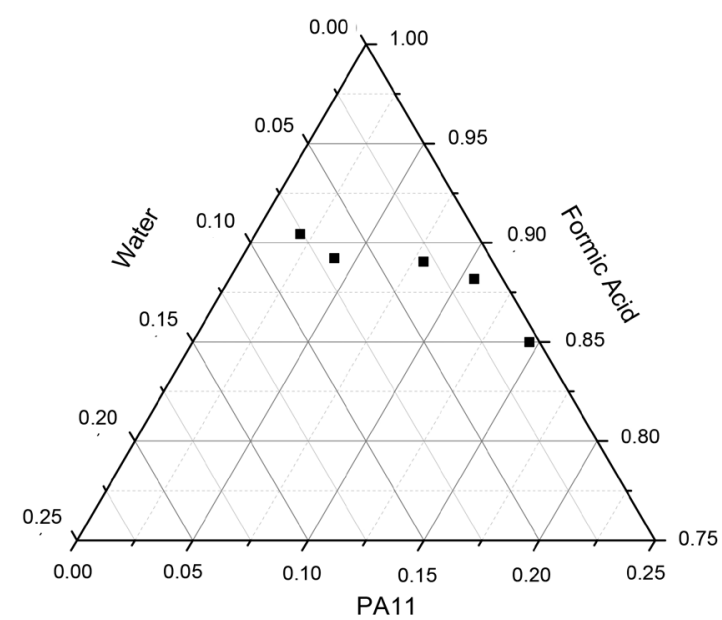

Figure 1. The cloud point curve represented in the ternary diagram of PA11/ $\mathrm{FA} / \mathrm{H}_{2} \mathrm{O}$ system

\section{Morphological and structural analysis of porous films}

The polyamide 11 dense film (PA1 $1_{\text {film }}$ ) was analyzed by Scanning Electron Microscopy (SEM) and using the Image $J^{\circledR}$ Software $^{34}$ it was possible to determine the average film thickness equal to $0.23 \mathrm{~mm}$. The dense film has a homogeneous structure without the presence of pores, which according to IUPAC Golden Book ${ }^{6}$ is classified as a dense. The morphology of the porous films with polymer concentration of 15,20 and $25 \mathrm{wt} \%$, respective namely by $\mathrm{MPA}_{15}, \mathrm{MPA}_{20}$ and $\mathrm{MPA}_{25}$, was investigated by SEM. Figure 2 shows the porous film microscopy of the upper surface (which was in contact with non-solvent) and the cross section. The porous films show similarity in the porous structure of the upper surface and was observed a dependent between polymer concentration and the pores distribution in sub-layer. We note that increase of polymer concentration results in decrease of the number of pores and its dimension on porous films upper surface. Basically, porous films prepared by NIPS are obtained by induction of temperature and diffusion processes, where the polymer-solution is separated into two distinct phases: the polymer rich phase (porous film matrix) and the solvent rich phase (pore structure). ${ }^{2,19}$ Therefore the polymer concentration in casting solution will influence the final porous film morphology. During the coagulation bath, the polymer chain in casting-solution has a hydrophobic behavior in presence of non-solvent. With an increase amount of water, consequently the polarity of the bath solution was improving. The polymer surface areas decrease by the reorganization of polymer chains because of weak intermolecular forces, minimizing the repulsive forces between the polymer chain and water.

Another influence in porous film morphology is de miscibility of solvent and non-solvent. Usually a high affinity between the

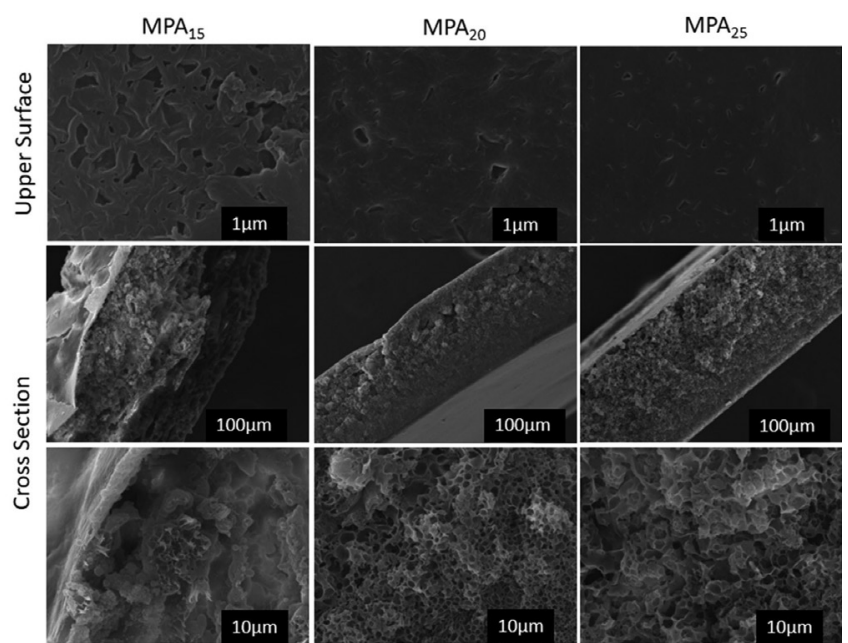

Figure 2. SEM microscopy of the $M P A_{15}, M P A_{20}$ and $M P A_{25}$ porous films of the upper surface and cross section

solvent and the non-solvent will result in instantaneous mixing producing pores in porous film. Research of Strathmann et al..$^{35}$ and Mazinani et al..$^{20}$ showed that the time between immersion of the polymer-solution in bath coagulation and the polymer precipitation directly influences the membrane morphology. Fast precipitations generate more open porous structures known as macrovoids that, according to the literature, present low salt rejection and high water flow. ${ }^{33}$ Thus the formation of a porous film with a macrovoid structure occurred due to kinetic parameters during phase inversion in the coagulation bath, where the diffusion rate between solvent and nonsolvent was faster. This behavior is showed by $\mathrm{MPA}_{15}$ porous film and the presence of macrovoids was resulted by the low polymer concentration and the influence of kinetic parameters during the rearrangement of the polymer chain. ${ }^{12}$

As polyamide 11 has a large hydrophobic region, during the coagulation bath its chains are reorganized to reduce the surface area in contact with water. Thus, as indicated in the literature, ${ }^{25,35}$ it was concluded that a rapid polymer precipitation occurred on the $\mathrm{MPA}_{15}$ porous film. The polymer solution of $\mathrm{MPA}_{15}$ porous film has the lowest concentration, as a result, the solvent dissolves better the polymer in the casting solution. That induces de formation of macrovoids in porous film morphology.

Slow precipitations generate more closed-porous with sponge structures that produces a porous film with high salt rejection and low water flow. Furthermore, as shown in Figure 2, the pore structure was more regular in the cross section of the porous films $\mathrm{MPA}_{20}$ and $\mathrm{MPA}_{25}$ with the highest polymer concentration. Typically, in the solutions with high viscosity, the formation of structures with microspores occurred, resulting from the delay in the diffusion between the solvent and non-solvent. ${ }^{20}$ The polymer higher concentration there is not enough solvent and non-solvent exchange in the casting solution during the phase separation and solidification process, so the porous film gravimetric porosity is reduced.

The $\mathrm{MPA}_{20}$ and $\mathrm{MPA}_{25}$ porous films have a higher polymer concentration in the coagulation bath, so the polymer chains have more contact with each other, generating a greater number of intermolecular bonds. For this reason, smaller pores with regular and spongy structures are formed by the influence of thermodynamic parameters of this polymer chain rearrangement. Note that the $\mathrm{MPA}_{25}$ porous film has a higher concentration of polymer, therefore, in this case a higher viscosity solution causing less solubilization of the polymer chain by the solvent. This results in higher polymeric nucleation points compared to the $\mathrm{MPA}_{20}$ porous film. ${ }^{36}$ 

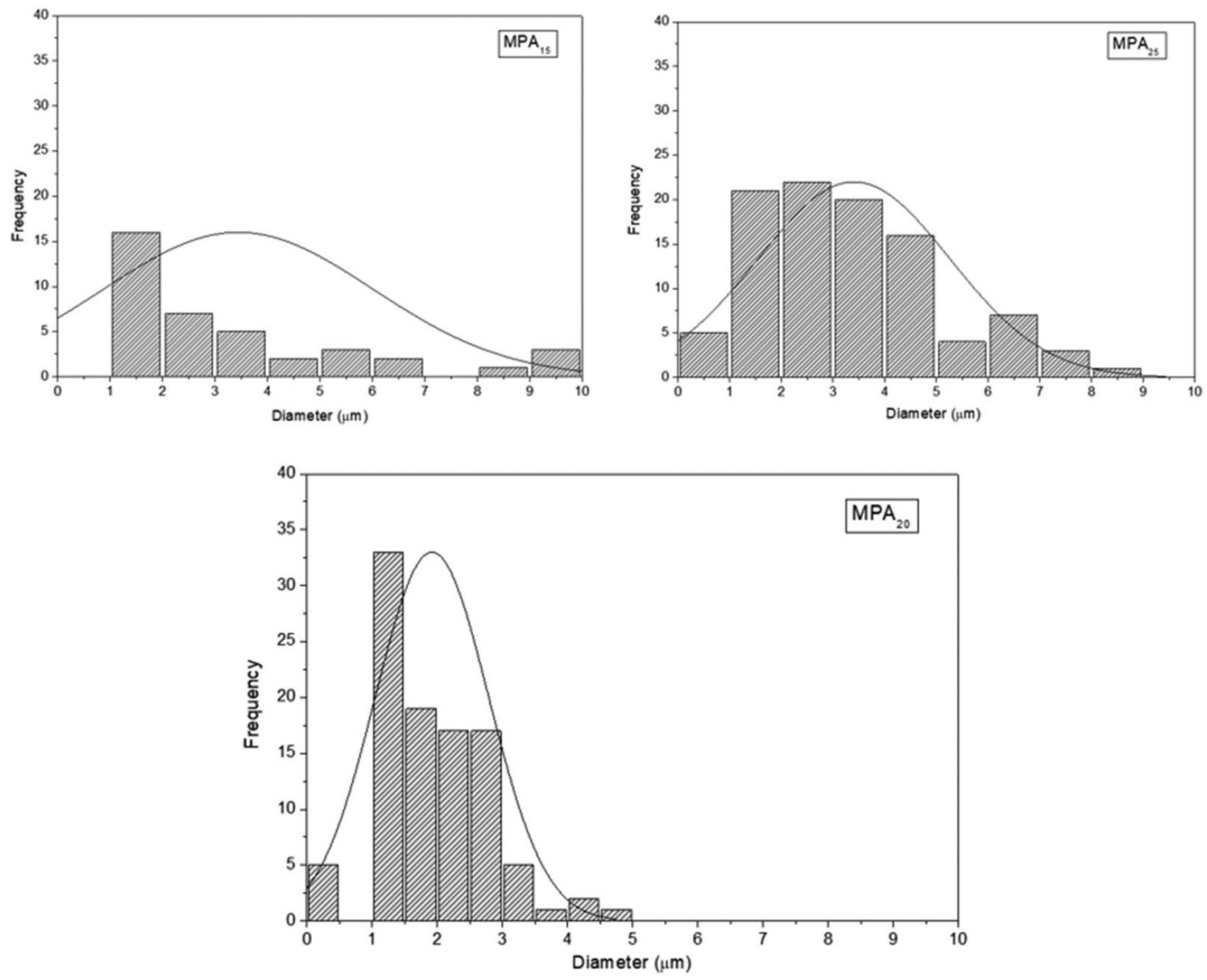

Figure 3. Histogram of the pore size of the $M P A_{15}, M P A_{20}$ and $M P A_{25}$ porous films

The cross-sectional SEM images of the $\mathrm{MPA}_{15}, \mathrm{MPA}_{20}$ and $\mathrm{MPA}_{25}$ porous films were treated with the Image ${ }^{\circledR}$ software. ${ }^{34}$ The average thickness of the porous films was $0.40 \mathrm{~mm}$, being calculated by image analysis with nine repetitions for each porous film. The estimate of the pore size was performed with Image $J^{\circledR}$ and measuring by the diameter of the circular pores found in each porous film. The histogram of the pore size distribution of the porous films is shown in Figure 3. All porous films have pore size predominantly between 0-10 $\mu \mathrm{m}$. The $\mathrm{MPA}_{15}$ porous film has the lowest frequency of pore size in this range as result of the formation of macrovoids. On the other hand, the $\mathrm{MPA}_{20}$ porous film has a smaller distribution of the pore size in the range of $0-10 \mu \mathrm{m}$ having a higher frequency of pores in diameter equal to $2.0 \mu \mathrm{m}$. In addition, the $\mathrm{MPA}_{25}$ porous film have higher frequency of the pores in diameter of $3.0 \mu \mathrm{m}$. This difference between $\mathrm{MPA}_{20}$ and $\mathrm{MPA}_{25}$ porous films was evidenced by SEM analysis described by Figure 2 .

The use of porous film filtration for liquid phases can be divided according to porosity into four categories: Microfiltration-MF (pores from 50 to $1000 \mathrm{~nm}$ ), Ultrafiltration-UF (pores from 1 to $100 \mathrm{~nm}$ ), Nanofiltration-NF (pores up to $2 \mathrm{~nm}$ ) and Reverse Osmosis-OR (pores smaller than $2 \mathrm{~nm}$ ). So, this methodology by image analyses shows that the porous films $\mathrm{MPA}_{20}$ and $\mathrm{MPA}_{25}$ have the porosity of Microfiltration category. ${ }^{19}$ This morphological analyses demonstrate that polyamide 11 membranes has a great potential to be implemented in permeation process. Although, other complementary studies of pores size by permeation analysis is necessary.

The crystallinity study of porous film was carried out by X-ray diffraction analysis (XRD) and the diffractograms are described in Figure 4. Polyamide 11 is a semi crystalline polymer that has polymorphism with several crystalline phases. Three distinct crystalline structures of PA11 are reported in the literature: ${ }^{37} \alpha, \beta$ and $\gamma$ forms. The $\alpha$ form has a triclinic crystalline structure (with network parameter: $\mathrm{a}=0.49 \mathrm{~nm}, \mathrm{~b}=0.52 \mathrm{~nm}, \mathrm{c}=3.23 \mathrm{~nm}, \alpha=50^{\circ}$, $\beta=77^{\circ}$ and $\gamma=64^{\circ}$ ), the $\beta$ form also has a triclinic structure (with network parameter: $\mathrm{a}=0.49 \mathrm{~nm}, \mathrm{~b}=0.802 \mathrm{~nm}, \mathrm{c}=3.23 \mathrm{~nm}, \alpha=90^{\circ}$, $\beta=77^{\circ}$ and $\gamma=67^{\circ}$ ) and the $\gamma$ shape has a special pseudo-crystalline structure-hexagonal. The intrinsic proprieties of PA precipitation at coagulation bath are significantly affected by polymorphism.

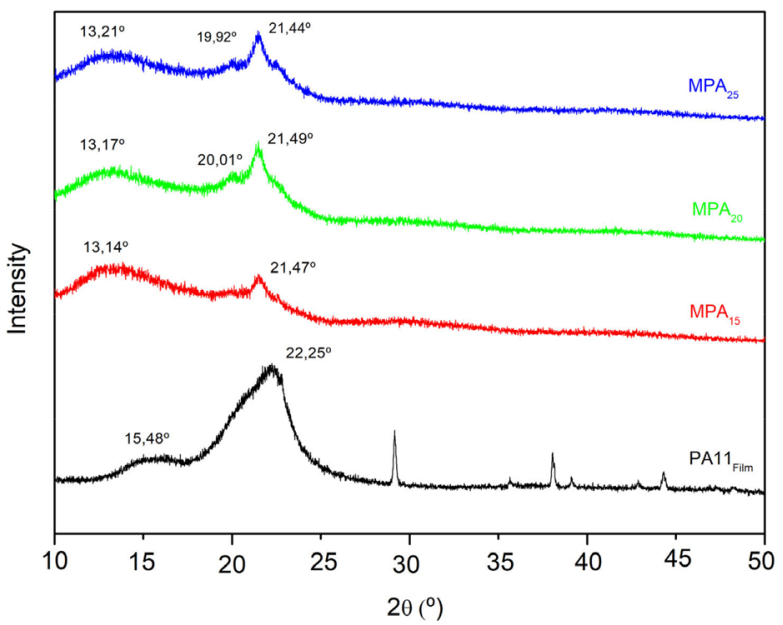

Figure 4. Diffractograms of the $M P A_{15}, M P A_{20}$ and $M P A_{25}$ porous films and PA11 $1_{\text {Film }}$ dense film

A study by Murthy ${ }^{38}$ associates the predominance of the $\alpha$ form during slow crystallizations and thermodynamic domain and the 
$\gamma$ form is associated with fast crystallization systems with kinetic domain. ${ }^{37}$ The crystalline $\alpha$ form has the most thermodynamically stable configuration of polyamide 11. Its triclinic structure allows the antiparallel ordering of the polymer chains and the hydrogen bonds form planes along the chain's connection axis. The $\gamma$ form, on the other hand, presents a random distribution of hydrogen bonds along the polymer chain, favoring the influence of dipole moments on the stability of the crystalline structure. ${ }^{37}$

The $\mathrm{MPA}_{15}$ porous film showed a diffraction peak $2 \theta=21.47^{\circ}$ for the $\gamma$ pseudo hexagonal form, whose $2 \theta \approx 21.5^{\circ}$ in the literature. ${ }^{39}$ Also, the analysis of the morphology performed by the SEM performed previously on this porous film allows demonstrating that the formation of macrovoids is result of the kinetic process in the polymer precipitation during the porous film formation by the action of the coagulation bath. In the diffractograms of the $\mathrm{MPA}_{20}$ and $\mathrm{MPA}_{25}$ porous films, it is possible to observe the corresponding peak of the $\alpha$ form close to $2 \theta=20^{\circ}$, agreeing with the values of $2 \theta=20.5^{\circ}$ already reported in the literature. ${ }^{39}$ This structural analysis of the crystalline forms of the $\mathrm{MPA}_{20}$ and $\mathrm{MPA}_{25}$ porous films is compatible with the morphological analysis previously performed by the SEM images, where the structure of the spongy pores indicates the predominance of the $\alpha$ phase, which is thermodynamically more stable. In addition to the crystalline domains, the porous films are composed of regions with pores and amorphous regions in the polymeric matrix. This region can be seen in porous film diffractograms by the diffraction angle at $2 \theta=13^{\circ} .{ }^{36}$ The peaks of the PA $11_{\text {film }}$ diffractograms above $2 \theta=25^{\circ}$ refer to the aluminium sample holder.

To complement the structure and crystallinity analysis, the polyamide 11 dense film and porous films were analyzed by Differential Scanning Calorimetry (DSC). The results of the DSC analysis are shown in Figure 5, where the typical thermal curve of polyamide 11 is observed with similar profile curves for the porous films $\mathrm{MPA}_{15}, \mathrm{MPA}_{20}, \mathrm{MPA}_{25}$ and PA11 $1_{\text {film }}$ dense film. The polyamide 11 dense film displays the melting temperature $(\mathrm{Tm})$ at $188.29^{\circ} \mathrm{C}$ (literature values of $\mathrm{Tm}=189.0^{\circ} \mathrm{C}$ ).${ }^{18} \mathrm{An}$ additional exothermic peak was observed in the porous film curves between the temperature of 178.10 and $188.54{ }^{\circ} \mathrm{C}$. In general, when crystallization occurs in the $\gamma$ form it is immediately converted to the more stable crystalline $\alpha$ form and the secondary exothermic peak appears in the DSC curves..$^{38,40-42}$

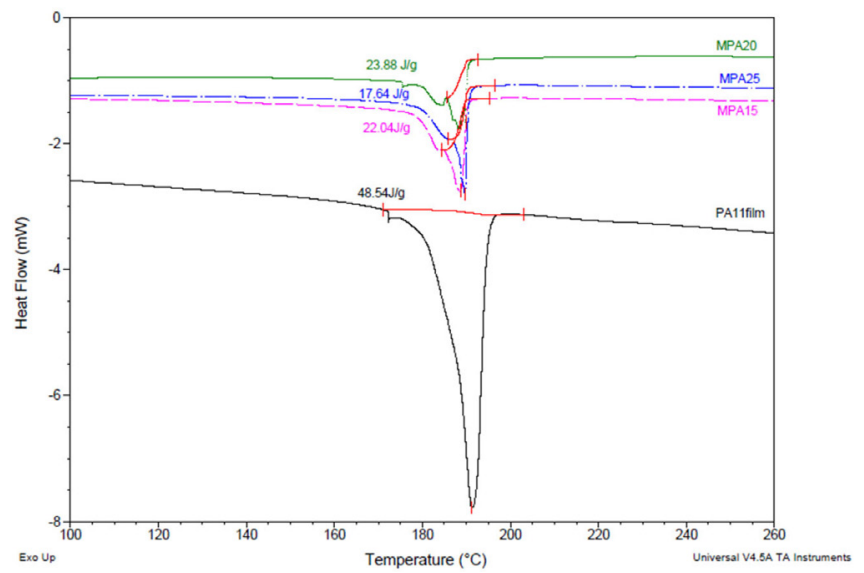

Figure 5. DSC analysis curves for the melting temperature $\left(T_{m}\right)$ for the $P A 11_{\text {fim }}$ dense film and $M P A_{15}, M P A_{20}$ and $M P A_{25}$ porous films

The degree of crystallinity $\left(\mathrm{X}_{\mathrm{cr}}\right)$ was determined using the melting temperature and enthalpy data of the DSC curve available in Table 3 and in Equation 1 previously presented. Tables $1 \mathrm{~S}$ and $2 \mathrm{~S}$ in supplementary material have a complete of statistic data of melt temperature and enthalpy measurements of each triplicate. The
Table 3. Result of DSC analysis for PA $11_{\text {film }}$ dense film and porous films

\begin{tabular}{ccccc}
\hline Sample & $\mathrm{T}_{\mathrm{m} 1 \mathrm{med}}\left[{ }^{\circ} \mathrm{C}\right]$ & $\mathrm{T}_{\mathrm{m} 2 \mathrm{med}}\left[{ }^{\circ} \mathrm{C}\right]$ & $\begin{array}{c}\Delta \mathrm{H}_{\text {med }}[\mathrm{J} / \mathrm{g}] \\
( \pm \text { Standard } \\
\text { Error })\end{array}$ & $\begin{array}{c}\mathrm{Xcr}_{\text {med }}[\%] \\
( \pm \text { Standard } \\
\text { Error })\end{array}$ \\
\hline${\mathrm{PA} 11_{\text {film }}}$ & 188.29 & - & $49.8( \pm 3.3)$ & $22.0( \pm 1.4)$ \\
$\mathrm{MPA}_{15}$ & 178.10 & 188.64 & $20.0( \pm 1.0)$ & $8.8( \pm 0.4)$ \\
$\mathrm{MPA}_{20}$ & 182.64 & 188.50 & $22.8( \pm 4.0)$ & $10.1( \pm 1.7)$ \\
$\mathrm{MPA}_{25}$ & 182.02 & 187.58 & $32.1( \pm 9.0)$ & $14.2( \pm 4.0)$ \\
\hline
\end{tabular}

melt temperature of porous films did not variety much in function of polymer concentration. Nevertheless, the enthalpy values showed a decrease in function of polymer improvement. The $X_{\mathrm{cr}}$ values of $\mathrm{MPA}_{15}, \mathrm{MPA}_{20}$ and $\mathrm{MPA}_{25}$ was, respectively, $8.8( \pm 0.4), 10.1( \pm 1.7)$ and $14.2( \pm 4.0) \%$. The PA $11_{\text {film }}$ showed a degree of crystallinity of $22.0( \pm 1.4) \%$.

Summing up, the porous films showed a lower degree of crystallinity than the polyamide 11 dense film, which means that the porous films may be more prone to permeation; therefore, studies indicate that the amorphous part of the polymeric matrix is responsible for the transition of the permeate in the porous film structure. ${ }^{12}$

\section{Mechanical testing of porous films}

Stress-strain tests are reported to be highly sensitive to changes in mechanical properties in porous films, which may be a consequence of intermolecular interactions of polymer chains. ${ }^{43}$ The stress-strain curves of the tensile tests obtained for the polyamide 11 dense film and the $\mathrm{MPA}_{15}, \mathrm{MPA}_{20}$ and $\mathrm{MPA}_{25}$ porous films are shown in Figure 6. The stress-strain test allowed the association between the concentration of the polymer and porous film structure. Using the polyamide dense film as a parameter was possible to relate to the data of Young's Module (the slope at the origin of the curve) and molecular interaction.

The porous films in the $30^{\circ} \mathrm{C}$ isotherm exhibit a behavior where the Young's modulus depends directly on the polymer concentration. The PA $11_{\text {film }}$ stress-strain curve showed a characteristic profile of hard materials, with Young's Modulus equal to 16.0 MPa. The film presented good mechanical resistance with low deformation when high tension was applied. The stress-strain curves of the porous films showed similar mechanical behavior to materials with elastic and plastic characteristics. It was found that the Young's modulus values, related to the elastic part of the curve, are 4.10, 5.97 and 7.00 $\mathrm{MPa}_{\text {for }} \mathrm{MPA}_{15}$, $\mathrm{MPA}_{20}$ and $\mathrm{MPA}_{25}$ porous films, respectively. The increase in polymer concentration promotes an increase in the intermolecular interactions of the amide, carbonyl and hydrocarbon groups in polymer chain. Previously discussed, the $\mathrm{MPA}_{15}$ porous film presented macrovoids in its microstructure, which consequently is the result of the lowest polymer concentration. The polymeric chains acquired greater mobility, increasing the free volume, leading to a decrease in the glass transition temperature and a decrease in Young's modulus. ${ }^{44,45}$

However, in the $\mathrm{MPA}_{20}$ and $\mathrm{MPA}_{25}$ porous films, the formation of plastic domains arising from the interaction between the linear part of the polymer chain of the polyamide was observed. As this interaction is maintained by Van der Waals forces, it allows the parallel displacement of the polymer chain, providing greater fluidity to the material and the greater resistance to deformation of these porous films, when compared to $\mathrm{MPA}_{15}$. It is noteworthy that the $\mathrm{MPA}_{20}$ and $\mathrm{MPA}_{25}$ porous films presented smaller pores with spongy structures and regular distribution formed by the influence of thermodynamic parameters of the rearrangement of the polymeric chain, where such behavior was verified by the morphological analysis previously discussed. 

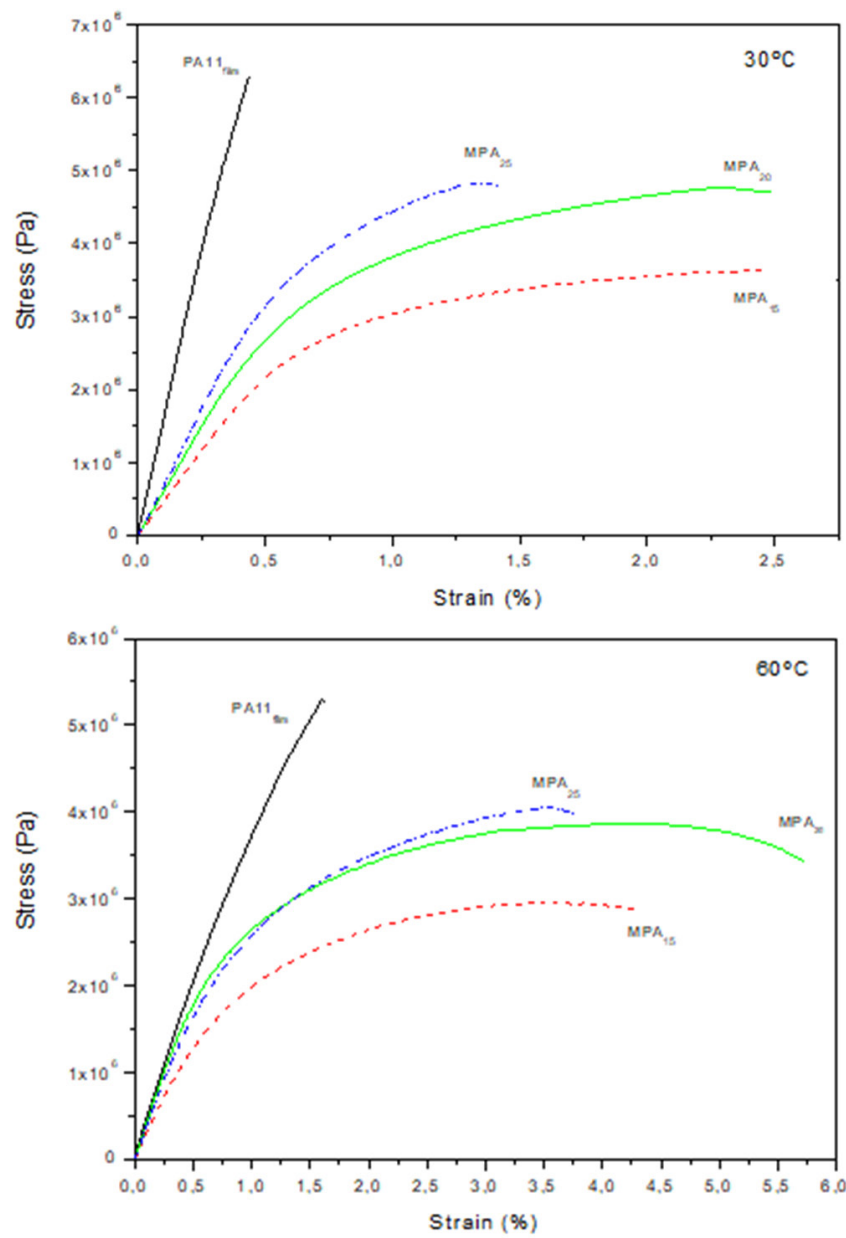

Figure 6. Stress-strain isotherms curve of $P A 11_{\text {film }}$ dense film and $M P A_{15}, M P A_{20}$ and $M P A_{25}$ porous films for temperature of $30^{\circ} \mathrm{C}$ and $60^{\circ} \mathrm{C}$

It should be noted that the porous films had a stiffness scale in the order: $\mathrm{MPA}_{25}>\mathrm{MPA}_{20}>\mathrm{MPA}_{15}$. The hardness scale is related to the area under the stress-strain curve and decreasing in the following order: $\mathrm{MPA}_{20}>\mathrm{MPA}_{25}>\mathrm{MPA}_{15}$. This behavior similar occurrence in the dispersion of crystalline microstructures in an amorphous polyamide matrix, resulting in improved mechanical properties, increasing the modulus of elasticity, tensile strength and reducing ductility. ${ }^{46}$

Figure 6 shows the stress-strain curve of the $60^{\circ} \mathrm{C}$ isotherm. The observed values of Young's modulus are 2.73, 3.96 and 3.68 MPa for $\mathrm{MPA}_{15}, \mathrm{MPA}_{20}$ and $\mathrm{MPA}_{25}$ porous films, respectively, and 4.29 $\mathrm{MPa}$ for the film. It is observed that these values are lower compared to those found for the $30^{\circ} \mathrm{C}$ isotherm. The temperature improvement, above the glazing temperature of polyamide $11\left(\mathrm{Tg}=42{ }^{\circ} \mathrm{C}\right),{ }^{47}$ increases the mobility of the polymeric chain and, consequently, decreases the material stiffness (indicated by the effective decrease in Young's modulus). ${ }^{27}$ However, the $\mathrm{MPA}_{20}$ porous film showed higher Young's modulus value. As the structure of this porous film has a better distribution of the pore size (in the range of $2.0 \mu \mathrm{m}$ as discussed in the SEM analysis), the increase in temperature had the lesser expressive impact on the microstructure of the polymer chains. Since this porous film already had a greater number of intermolecular interactions when compared to the $\mathrm{MPA}_{25}$ porous film. ${ }^{12}$

Mechanical analysis of cellulose fiber reinforced porous films was performed and Young's modulus values for 30 and $60{ }^{\circ} \mathrm{C}$ isotherms and the obtained data were organized in supplementary material. For the $30^{\circ} \mathrm{C}$ isotherm, it was observed that in all cellulose concentrations $(1.0,2.0$ and $4.0 \%)$ there was an increase in Young's modulus due to the increase in polymer concentration, as was observed for porous films at the same temperature. Cellulose fibers reinforced the rigidity of the porous films, decreasing the ductility and increasing the elastic modulus. ${ }^{25}$ The cellulose concentration of $2.0 \%$ is more rigid than 4.0. This is justified by the structure of the pores found in the $\mathrm{C}_{2} \mathrm{PA}_{20}$ porous film, which has smaller dimensions than the $\mathrm{C}_{4} \mathrm{PA}_{20}$ porous film, visualized by the SEM shown in Figure 7. The size of the pores effectively influenced the amount of molecular interactions carried out by the polymer chain, thus increasing the value Young's modulus. ${ }^{25}$

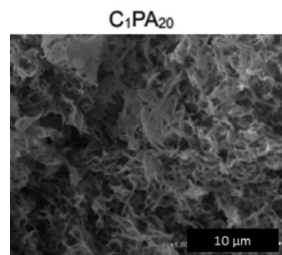

$\mathrm{C}_{2} \mathrm{PA}_{15}$

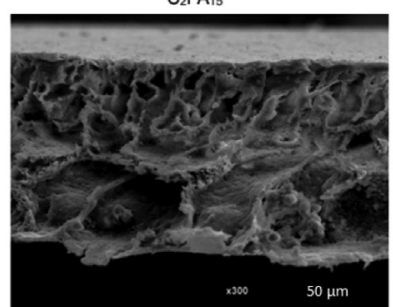

$\mathrm{C}_{2} \mathrm{PA}_{20}$

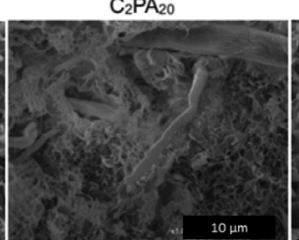

$\mathrm{C}_{4} \mathrm{PA}$

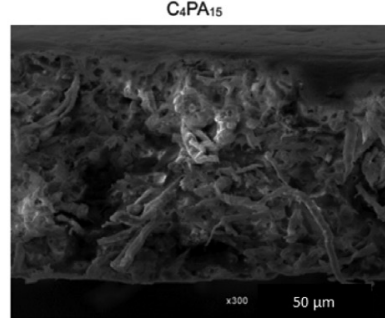

Figure 7. SEM microscopy of porous films with cellulose reinforcement $C_{1} P A_{20}$ $C_{2} P_{20}, C_{4} P A_{20}$, reinforcement $C_{2} P A_{15}$ and $C_{4} P A_{15}$

The microscopy shown in Figure 7 are porous films with 20 wt $\%$ of polyamide with addition of 1.0, 2.0 and $4.0 \%$ of cellulose. The presence of cellulose fibers in all porous films is observed. The thermodynamic behave of polymer precipitation was the same as the porous film matrix without adding cellulose reinforcement. As discussed in Morphological and structural analysis of porous films, the $\mathrm{MPA}_{20}$ porous film has morphology with smaller pores of regular and spongy structure formed by the influence of thermodynamic parameters during the coagulation bath.

Figure 7 presents SEM images of the porous films with 2.0 and $4.0 \mathrm{wt} \%$ cellulose reinforcement and $15 \mathrm{wt} \%$ concentration of the polyamide. These porous films also showed the formation of macrovoids demonstrating the kinetic domain of polymer precipitation during the coagulation bath. Thus evidencing that there was no influence of the cellulose fiber on the thermodynamic parameters of the ternary $\mathrm{PA} 11 / \mathrm{FA} / \mathrm{H}_{2} \mathrm{O}$ system during the process of rearrangement of the polymeric chain in the coagulation bath. For the reinforced porous films analyzed at $60{ }^{\circ} \mathrm{C}$ there were similarities in the mechanical behavior in reference to those submitted to $30{ }^{\circ} \mathrm{C}$. However, the values of Young's Module were lower, similar to what occurred for porous films without cellulose reinforcement that were influenced by the increase in temperature.

\section{CONCLUSIONS}

In summary, it was possible to demonstrate the preparation of polyamide 11 (PA11) porous films by phase inversion by induction of non-solvent (water) using formic acid (FA) as a solvent. The study of porous film morphology by SEM showed that higher concentrations of polymer resulted in larger pores and regular structure. The $\mathrm{MPA}_{20}$ and $\mathrm{MPA}_{25}$ porous films have a more defined structure, smaller pores with a spongy structure for implementation in separation processes with high salt rejection and low water flow. The XRD analysis showed that the $\mathrm{MPA}_{15}$ porous film has a peak close to $2 \theta=22^{\circ}$, indicating the predominance of the $\gamma$ phase in this porous film. In the diffractograms 
of the $\mathrm{MPA}_{20}$ and $\mathrm{MPA}_{25}$ porous films, it is possible to observe the corresponding peak of the $\alpha$ phase close to $2 \theta=21^{\circ}$. The DSC curve showed the melting temperature (Tm) of polyamide 11 dense film at $188.29^{\circ} \mathrm{C}$. An additional exothermic peak was observed in the porous film curves between 178.10 and $188.64{ }^{\circ} \mathrm{C}$, indicating the transition from $\gamma$ to $\alpha$ crystalline phase. It is concluded that crystallization occurs predominantly in the most stable $\alpha$ crystalline form. The polyamide1 1 porous films showed a lower degree of crystallinity than the PA $11_{\text {film }}$.

The stress-strain test shows that Young Modules increase because of improved polymer concentration. This increase occurs due to the increase in the concentration of polymers that promotes greater contact between the polymer chains, generating a greater number of intermolecular bonds. In the porous films with a concentration of 20 and $25 \mathrm{wt} \%$, the formation of plastic domains arising from the interaction between the linear part of the polymeric chain of the polyamide was observed.

Cellulose fibers reinforced the rigidity of the porous films, decreasing the ductility and increasing the elastic modulus. The cellulose concentration of $2.0 \%$ is shows more rigid than $4.0 \%$ in porous film reinforcement. The presence of cellulose fibers in all porous films is observed, whereas the polymeric matrix behaved the same as the porous film matrix without adding cellulose reinforcement. Thus evidencing that there was no influence of the cellulose fiber on the thermodynamic parameters of the ternary PA11/ $\mathrm{FA} / \mathrm{H}_{2} \mathrm{O}$ system during the process of rearrangement of the polymeric chain in the coagulation bath.

\section{SUPPLEMENTARY MATERIAL}

The Young Modules of porous films with and without cellulose reinforcement, and statistical data from DSC analyses are available at http://quimicanova.sbq.org.br, in PDF format, with free access.

\section{ACKNOWLEDGEMENTS}

The authors gratefully thank CAPES for MS scholarship, laboratory LUCCAR-UFES (Brazil) and NCQP-UFES (Brazil) for their technical support.

\section{REFERÊNCIAS}

1. Mohammad, A. W.; Teow, Y. H.; Ang, W. L.; Chung, Y. T.; OatleyRadcliffe, D. L.; Hilal, N.; Desalination 2015, 356, 226.

2. Nunes, S. P.; Peinemann, K.-V.; Membrane technology in the chemical industry, Wiley-VCH: Weinheim, 2001.

3. Dai, Z.; Ansaloni, L.; Deng, L.; Green Energy Environ. 2016, 1, 102.

4. Warsinger, D. M.; Chakraborty, S.; Tow, E. W.; Plumlee, M. H.; Bellona, C.; Loutatidou, S.; Karimi, L.; Mikelonis, A. M.; Achilli, A.; Ghassemi, A.; Padhye, L. P.; Snyder, S. A.; Curcio, S.; Vecitis, C. D.; Arafat, H. A.; Lienhard, J. H. A.; Prog. Polym. Sci. 2018, 81, 209.

5. Tan, X.; Rodrigue, D.; Polymers (Basel) 2019, 11, 1.

6. IUPAC Compendium of Chemical Terminology, Blackwell Scientific Publications: Oxford, 2019.

7. Basile, A.; Cassano, A.; Rastogi, N. K.; Advances in Membrane Technologies for Water Treatment: Materials, Process and Applications, $1^{\text {a }}$ ed., Elsevier Sciencer Publishers: Amsterdam, 2015.

8. Bano, S.; Mahmood, A.; Kim, S.-J.; Lee, K.-H.; J. Mater. Chem. A 2015 , 3, 2065.

9. Saleh, T. A.; Gupta, V. K.; Sep. Purif. Technol. 2012, 89, 245.

10. Asempour, F.; Emadzadeh, D.; Matsuura, T.; Kruczek, B.; Desalination 2018, 439, 179.

11. Yu, S.; Liu, M.; Ma, M.; Qi, M.; Lü, Z.; Gao, C.; J. Memb. Sci. 2010, $350,83$.
12. Aulova, A.; Simon, Ž.; Planin, O.; Kristl, A.; Emri, I.; J. Memb. Sci. 2018, 562, 67.

13. Bugatti, V.; Vertuccio, L.; Viscusi, G.; Gorrasi, G.; Nanomaterials 2018 , $8,139$.

14. Winnacker, M.; Rieger, B.; Macromol. Rapid Commun. 2016, 37, 1391.

15. Bezerra, E. B.; Melissa, A.; Leite, D.; Araújo, E. M.; Jeferson, T.; Mélo, A. D.; Polímeros 2014, 24, 381.

16. Ulbricht, M.; Polymer 2006, 47, 2217.

17. Poletto, P.; Duarte, J.; Thürmer, M. B.; Santos, V.; Zeni, M. C.; Mat. Res. 2011, 14, 547.

18. Behler, K.; Havel, M.; Gogotsi, Y.; Polymer 2007, 48, 6617.

19. Hilal, N.; Fauzi, A.; Wright, C.; Membrane Fabrication, CRC PressTaylor \& Francis Group: Broken Sound Parkway, New York, 2015.

20. Mazinani, S.; Darvishmanesh, S.; Ehsanzadeh, A.; Van Der Bruggen, B.; J. Memb. Sci. 2017, 526, 301.

21. Benaducci, D.; Branciforti, M. C.; Rev. Mater. 2016, 21, 898.

22. Theivasanthi, T.; Anne Christma, F. L.; Toyin, A. J.; Gopinath, S. C. B.; Ravichandran, R.; Int. J. Biol. Macromol. 2018, 109, 832.

23. Farias, A. G.; Monografia, Universidade Federal do Espírito Santo, Brasil, 2017

24. Qua, E. H.; Hornsby, P. R.; Plast. Rubber Compos. 2011, 40, 300.

25. Ortega, H. O.; Alberto, M.; Mutj, P.; Tarr, Q.; Polymers (Basel) 2017, 9 , 1 .

26. Zahid, M.; Rashid, A.; Akram, S.; Rehan, Z. A.; Razzaq, W.; J. Membr. Technol. 2018, 8, 1

27. Kawano, Y.; Wang, Y.; Palmer, R. A.; Aubuchon, S. R.; Polímeros 2002, $12,96$.

28. Canevarolo Jr., S. V.; Técnicas de caracterização de polímeros, Artliber: São Paulo, 2017.

29. Menard, K. P.; Dynamic Mechanical Analysis A Practical Introduction, $2^{\mathrm{a}}$ ed., CRC Press: Boca Raton, 2008.

30. Holda, A. K.; Vankelecom, I. F. J.; J. Appl. Polym. 2013, 132, 1.

31. Holda, A. K.; Aernouts, B.; Saeys, W.; Vankelecom, I. F. J.; J. Memb. Sci. 2013, 442, 196.

32. Cheremisinoff, N. P.; Polymer characterization: laboratory techniques and analysis, William Andrew, 1996.

33. Guillen, G. R.; Pan, Y.; Li, M.; Hoek, E. M. V.; Ind. Eng. Chem. Res. 2011, 50, 3798

34. Abràmoff, M. D.; Magalhães, P. J.; Ram, S. J.; Biophotonics Int. 2004, 11,36 .

35. Strathmann, H.; Kock, K.; Desalinisation 1977, 21, 241.

36. Mago, G.; Kalyon, D. M.; Fisher, F. T. N.; Polym. Phys. 2011, 49, 1311.

37. Pepin, J.; Macromolecules (Washington, DC, U. S.). 2016, 49, 564.

38. Murthy, N. S.; J. Polym. Sci., Part B: Polym. Phys. 2006, 44, 1763.

39. Xiao, X.; Cai, Z.; Qian, K.; J. Polym. Res. 2017, 24, 1.

40. Peinemann, K.-V.; Nunes, S. P.; Membrane Technology in the Chemical Industry. Wiley-VCH: Weinheim, 2001.

41. Martino, L.; Basilissi, L.; Farina, H.; Aldo, M.; Zini, E.; Di, G.; Scandola, M.; Eur. Polym. J. 2014, 59, 69.

42. Dhanalakshmi, M.; Lele, A. K.; Jog, J. P.; Mater. Today Commun. 2015, 3,141 .

43. Narducci, R.; Chailan, J. F.; Fahs, A.; Pasquini, L.; Di Vona, M. L.; Knauth, P.; J. Polym. Sci., Part B: Polym. Phys. 2016, 54, 1180.

44. Yang, B.; Huang, W. M.; Li, C.; Li, L.; Polymer 2006, 47, 1348.

45. Correia, C. O.; Caridade, S. G.; Mano, J. F.; Polymers (Basel) 2014, 6 , 1178.

46. Song, L.; Zhu, T.; Yuan, L.; Zhou, J.; Zhang, Y.; Wang, Z.; Tang, C.; Nat. Сотmun. 2019, 10, 1.

47. Mark, J. E.; Polymer Data Handbook, Oxford University Press: New York, 1999 